\title{
Long-lasting effects of land use history on soil fungal communities in second-growth tropical rain forests
}

\author{
Benedicte Bachelot, ${ }^{1,6}$ María Uriarte, ${ }^{1}$ Jess K. Zimmerman, ${ }^{2}$ Jill Thompson,,${ }^{2,3}$ Jonathan W. LefF, ${ }^{4}$ Ava Asiait ${ }^{5}$ \\ Jenny Koshner, ${ }^{5}$ and Krista McGuire ${ }^{1,5}$ \\ ${ }^{1}$ Department of Ecology, Evolution and Environmental Biology, Columbia University, 1200 Amsterdam Avenue, New York, \\ New York 10027 USA \\ ${ }^{2}$ Department of Environmental Sciences, University of Puerto Rico, Río Piedras Campus, San Juan, Puerto Rico 00936 USA \\ ${ }^{3}$ Centre for Ecology \& Hydrology, Bush Estate, Penicuik, Midlothian EH26 OQB UK \\ ${ }^{4}$ Department of Ecology and Evolutionary Biology, Cooperative Institute for Research in Environmental Sciences, University of \\ Colorado Boulder, 1900 Pleasant street, 334 UCB, Boulder, Colorado, 80309 USA \\ ${ }^{5}$ Department of Biology, Barnard College, Columbia University, New York, New York 10027 USA
}

\begin{abstract}
Our understanding of the long-lasting effects of human land use on soil fungal communities in tropical forests is limited. Yet, over $70 \%$ of all remaining tropical forests are growing in former agricultural or logged areas. We investigated the relationship among land use history, biotic and abiotic factors, and soil fungal community composition and diversity in a second-growth tropical forest in Puerto Rico. We coupled high-throughput DNA sequencing with tree community and environmental data to determine whether land use history had an effect on soil fungal community descriptors. We also investigated the biotic and abiotic factors that underlie such differences and asked whether the relative importance of biotic (tree diversity, basal tree area, and litterfall biomass) and abiotic (soil type, $\mathrm{pH}$, iron, and total carbon, water flow, and canopy openness) factors in structuring soil fungal communities differed according to land use history. We demonstrated longlasting effects of land use history on soil fungal communities. At our research site, most of the explained variation in soil fungal composition $\left(R^{2}=18.6 \%\right)$, richness $\left(R^{2}=11.4 \%\right)$, and evenness $\left(R^{2}=10 \%\right)$ was associated with edaphic factors. Areas previously subject to both logging and farming had a soil fungal community with lower beta diversity and greater evenness of fungal operational taxonomic units (OTUs) than areas subject to light logging. Yet, fungal richness was similar between the two areas of historical land use. Together, these results suggest that fungal communities in disturbed areas are more homogeneous and diverse than in areas subject to light logging. Edaphic factors were the most strongly correlated with soil fungal composition, especially in areas subject to light logging, where soils are more heterogenous. High functional tree diversity in areas subject to both logging and farming led to stronger correlations between biotic factors and fungal composition than in areas subject to light logging. In contrast, fungal richness and evenness were more strongly correlated with biotic factors in areas of light logging, suggesting that these metrics might reflect long-term associations in old-growth forests. The large amount of unexplained variance in fungal composition suggests that these communities are structured by both stochastic and niche assemblage processes.
\end{abstract}

Key words: forest soil fungi; high-throughput sequencing; land use history; tropical forest; Luquillo Forest Dynamics Plot (LFDP); Puerto Rico.

\section{INTRODUCTION}

Soil fungi are critical to the functioning of forests, playing an important role in carbon sequestration (Coleman and Crossley 1996, Clemmensen et al. 2015) and in structuring plant communities (Bagchi et al. 2014, Liang et al. 2015). Despite the recognized importance of fungi for these ecosystems, the factors that structure soil fungal communities are poorly understood in tropical forests

Manuscript received 29 July 2015; revised 4 February 2016; accepted 10 February 2016. Corresponding Editor: R. L. Sinsabaugh.

6E-mail: bmb43@duke.edu compared to temperate forests (Frey et al. 2004, Fierer and Jackson 2006, Lauber et al. 2008, Öpik et al. 2010). This gap in knowledge reflects the difficulties associated with characterizing soil fungal communities given their inconspicuousness and high diversity in tropical rainforests and the challenge of accounting for the myriad factors that can influence variation in soil fungal communities.

Abiotic factors can shape soil fungal community composition directly by altering biochemical and physical conditions, or indirectly by affecting the plant communities on which fungi depend. Soil physical, chemical, and nutritional properties have been recognized as the main drivers of soil microbial community structure (Garbeva et al. 2004, Waldrop et al. 2006, Lauber et al. 
2008). Soil carbon affects soil fungal decomposers (de Graaff et al. 2010, Chapin et al. 2011) and arbuscular mycorrhizal (AM) fungi by enhancing their mineral nutrient uptake (Leigh et al. 2009) and by influencing plant growth (Zink and Allen 1998). Other soil nutrients, such as iron, shape soil fungal communities by influencing wood decomposition rates (Hall and Silver 2013) and by potentially toxic effects on plants and fungi $(\mathrm{Li}$ and Christie 2001). Additionally, light availability and soil $\mathrm{pH}$ and moisture can influence community composition of fungal decomposers (DeAngelis et al. 2013), pathogens (Prusky and Yakoby 2003), and mycorrhizal fungi (Zheng et al. 2015).

Soil fungal communities are also shaped by the local plant community, which provides them with resources and acts as hosts for some fungal groups (Ferrer and Gilbert 2003, McGuire et al. 2011, Wardle et al. 2011, Mueller et al. 2014, Urbanová et al. 2015). The quantity and nutritional quality of litter produced by the plant community may favor specific soil fungi (Gholz et al. 2000), thereby structuring fungal community composition (Prescott and Grayston 2013). Plant community characteristics might also affect fungal symbionts that exhibit some degree of host-plant preferences (Husband et al. 2002a, b, Peay et al. 2013, Toju et al. 2013, Tedersoo et al. 2014, Martínez-García et al. 2015). Overall, the importance of abiotic and biotic factors in shaping soil fungal communities vary across environment (Garbeva et al. 2004). The reasons underlining this variation remain unclear but could be associated with variation in environmental conditions and heterogeneity.

In the absence of long-term replicated experiments, successional tropical forests represent a useful system to study the biotic and abiotic factors that underlie land use impacts on the composition and structure of soil fungal communities. Human land use can alter soil carbon (Marín-Spiotta et al. 2008) and soil pH (Guariguata and Ostertag 2001), key drivers of soil fungi. For example, conversion of forest to crops can reduce soil carbon, whereas conversion of forest to pasture can increase soil carbon (Marín-Spiotta et al. 2008). In addition, land use might homogenize soil properties via soil mixing or altered vegetation-mediated soil feedbacks (Fraterrigo and Turner 2005). Several studies in temperate forests have shown that intensive land use may reduce within-stand spatial heterogeneity in abiotic factors such as soil water content, $\mathrm{pH}$, and nutrients (Fraterrigo and Turner 2005, Flinn and Marks 2007, Vellend et al. 2007). Soil fungi are sensitive to small-scale heterogeneity in abiotic factors (Kliromonos et al. 1999, Martiny et al. 2006, Barberán et al. 2015, Waring et al. 2016). This small-scale sensitivity could be explained if higher heterogeneity in abiotic factors results in greater availability of fungal niches and/or greater fungal resource limitation. Therefore, loss of environmental heterogeneity might result in a slight decrease in the importance of abiotic factors in structuring soil fungal communities, resulting from a decrease in fungal niches and/or limiting conditions.

The hypothesis of homogenization has also been proposed for the biotic community (Vellend et al. 2007) but has received mixed support (Grman et al. 2015). However, tropical rain forests in areas subject to human activities contain a mixture of tree species of various successional stages (Chazdon 2003). As a result, tree species in secondgrowth forests can span a greater range of leaf and wood traits than those growing in old-growth forests (Swenson et al. 2012). Plant species of distinct successional strategies and with different functional traits can favor distinct soil fungal communities (Ohsowski et al. 2014). Thus, greater plant trait functional diversity in forests recovering from more intense human land use could result in greater spatial heterogeneity of biotic factors shaping soil fungal communities in these areas relative to less disturbed areas. In summary, previously logged and farmed forests should exhibit more homogeneous abiotic conditions but a more heterogeneous biotic environment compared to old-growth forests.

In general, human land use has been shown to result in a decrease in soil fungal richness or diversity (Lodge 1997, Glinka and Hawkes 2014, Mueller et al. 2014). However, some studies have found greater soil fungal richness in areas with more intensive land use (e.g. Glinka and Hawkes 2014, Moora et al. 2014) or no effect of land use on fungal richness (e.g., Violiet al. 2008). Discrepancies may arise because of variation is sampling methodology or because land use effects on soil fungal communities are likely ecosystem-specific (Öpik et al. 2006) and nonlinear depending on the type of land use, its intensity, and time since disturbance (Lodge 1997, Carpenter et al. 2001, Glinka and Hawkes 2014, Mueller et al. 2014, Dickie et al. 2015, Vályi et al. 2015). For instance, Carpenter et al. (2001) found that arbuscular mycorrhizal fungal richness in pastures with low grazing intensity is higher than in second-growth tropical forest. However, change in sporulation and spore longevity could be responsible for change in the effects of land use across studies (Violi et al. 2008). Few studies have assessed long-lasting effects of land use on soil fungal communities (Hartmann et al. 2012) and fewer still have been conducted in the tropical forest biome (McGuire et al. 2015), which has undergone drastic deforestation followed by an expansion of second-growth forests in recent decades (FAO 2010).

We investigate the relationship among land use history, biotic and abiotic factors, and three components of soil fungal biodiversity, community composition, richness, and evenness, in the 16-ha Luquillo Forest Dynamics Plot (LFDP). We ask the following questions:

1. Do composition, richness, and evenness of soil fungal communities in a tropical forest differ between two areas with different intensities of historical human land use? We hypothesized that soil fungal community composition would vary with intensity of land use (ILU). Given conflicting results from past studies, we did not 
have an expectation about how soil fungal richness would vary between ILU. Fungal evenness, however, should be higher in a heterogeneous compared to a homogeneous environment. Since high ILU areas have a more homogeneous environment but more heterogeneous tree communities than low ILU areas, we did not have an expectation about how fungal evenness would vary between ILU.

2. Are the impacts of land use on soil fungal community composition, richness, and evenness explained by present-day variation in biotic or abiotic factors? We hypothesized that land-use driven differences in soil characteristics, light availability, and tree community composition would be associated with variation in soil fungal community metrics.

3. Does the relative importance of abiotic and biotic factors in structuring soil fungal communities differ among areas with high and low ILU? We expected that the relative importance of abiotic factors in structuring soil fungal communities would be higher in areas with low relative to high ILU due to high heterogeneity in soil characteristics, which could result in high fungal niche availability and/or high limiting conditions associated with edaphic factors. In contrast, we expected that greater functional tree diversity in areas of high ILU would lead to a greater importance of biotic factors in structuring soil fungal communities in these areas compared to areas of low ILU. This would arise if high biotic heterogeneity results in more available fungal niches or greater carbon source limitation than in areas with low biotic heterogeneity.

\section{Materials And Methods}

\section{Study site and field sampling}

The study site is the 16-ha LFDP (1820' N, 6549' W) in northeast Puerto Rico with elevation ranging between $333 \mathrm{~m}$ above sea level (a.s.1.) and $428 \mathrm{~m}$ a.s.l. (Thompson et al. 2002). Mean annual rainfall is $3500 \mathrm{~mm}$, classifying the forest as subtropical montane (Walsh 1996). All free-standing woody stems $>1 \mathrm{~cm} \mathrm{dbh}$ (diameter at $1.3 \mathrm{~m}$ height) have been mapped, identified to species, and measured every five years (Thompson et al. 2002). Human activities in the Luquillo forest ceased in 1934. We divided the plot into two categories: high (canopy cover $<80 \%$ ) and low (canopy cover $\geq 80 \%$ ) ILU (Fig. 1) determined from aerial canopy photos taken in 1936 (see Thompson et al. 2002). The high ILU was intensely logged and used for small-scale coffee and large fruit (e.g., mango) plantations. The low ILU was selectively logged but never cleared. The high ILU encompasses the northern two-thirds of the plots and has less rocky soils than the southern low ILU area that has a more rugged topography. These differences between ILU classes in the abiotic environment can be confounded with any effects of ILU so we included them in the analyses.

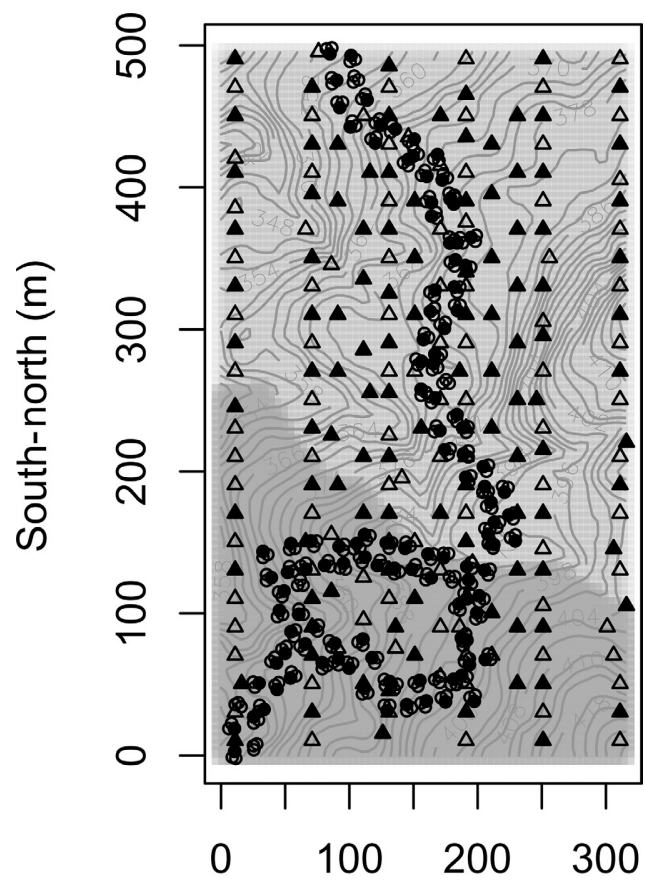

East-west (m)

FIG. 1. Map of the Luquillo plot and the locations of all of the $2-\mathrm{m}^{2}$ (triangle) and $1-\mathrm{m}^{2}$ (circle) seedling plots. Solid symbols indicate those seedling plots from which we collected soil samples. The dark area represents low intensity of past land use and the light section represents high intensity of past land use.

From May to July 2012, we sampled soil adjacent to 237 plots, in which naturally occurring seedlings, distributed systematically throughout the LFDP, were monitored (Fig. 1). This sampling enabled us to encompass the two areas of ILU and the different types of soil (Appendix S1: Fig. S1). Prior to soil sampling, we removed loose leaf litter $\left(\mathrm{O}_{\text {i-e }}\right.$ horizons) and decaying logs. To prevent cross-sample contamination, the soil corer was cleaned with $70 \%$ ethanol, and new gloves were used at each seedling plot. Soil cores (0-20 cm deep and $2.5 \mathrm{~cm}$ diameter) were pooled from the four corners of $1201 \times 1 \mathrm{~m}$ seedling plots and from two corners and $1 \mathrm{~m}$ along opposite sides of $1171 \times 2 \mathrm{~m}$ seedling plots, so that each sample represented the corners of a $1 \mathrm{~m}^{2}$ area. Pooling all soil samples within each plot minimized small-scale heterogeneity (Van der Gast et al. 2011). Pooled samples were located at least $20 \mathrm{~m}$ apart and distributed across the whole LFDP (Fig. 1). Samples were stored at $-20^{\circ} \mathrm{C}$ within $8 \mathrm{~h}$ of collection, shipped overnight to the laboratory at Barnard College, New York, New York, USA, where they were stored at $-20^{\circ} \mathrm{C}$ prior to molecular analysis.

We quantified a number of abiotic factors that can affect soil fungal communities: light availability (canopy openness), soil iron and carbon, soil $\mathrm{pH}$, potential water flow, and soil type (Table 1; Appendix S1: Fig. S2). Other 
TABLE 1. Distribution of the selected variables across land use history with the mean values and coefficient of variation in parentheses.

\begin{tabular}{|c|c|c|c|}
\hline \multirow[b]{2}{*}{ Variable } & \multicolumn{2}{|c|}{ Intensity of land use } & \multirow[b]{2}{*}{ Hypothesized effect } \\
\hline & High & Low & \\
\hline Adult tree diversity within $15 \mathrm{~m}$ radius (unitless) $\dagger+$ & $2.57(0.11)$ & $2.46(0.13)$ & host specificity, litter diversity \\
\hline Basal tree area $(\mathrm{BA})$ within $15 \mathrm{~m}$ radius $\dagger$ & $1809.53(0.14)$ & $1708(0.15)$ & $\begin{array}{l}\text { root biomass and carbon } \\
\text { allocation belowground }\end{array}$ \\
\hline Leaf litterfall biomass $\left(\mathrm{g} / \mathrm{m}^{2}\right)$ & $519.30(0.59)$ & $548.7(0.44)$ & aboveground nutrient inputs \\
\hline Canopy openness $(\%) \dagger+$ & $3.1(0.30)$ & $2.6(0.29)$ & $\begin{array}{l}\text { temperature, moisture and } \\
\text { plant tissue quality, tree } \\
\text { community }\end{array}$ \\
\hline Soil iron $(\mathrm{ppm}) \dagger+$ & $53.02(0.95)$ & $121.62(0.99)$ & $\begin{array}{l}\text { wood decomposition; toxicity } \\
\text { to plants and fungi }\end{array}$ \\
\hline Soil total carbon $(\%) \dagger+$ & $4.23(0.23)$ & $4.89(0.38)$ & $\begin{array}{l}\text { indicator of soil nutrient } \\
\text { availability and buffering } \\
\text { capacity }\end{array}$ \\
\hline Soil pH $(\log (\mathrm{mol} / \mathrm{L})) \dagger$ & $4.77(0.10)$ & $4.58(0.10)$ & $\begin{array}{l}\text { fungal metabolism and } \\
\text { functioning, tree community }\end{array}$ \\
\hline Water flow $\left(\mathrm{m}^{2}\right)$ & $0.62(1.08)$ & $0.67(0.87)$ & $\begin{array}{l}\text { affects soil erosion and } \\
\text { fertility, fungal metabolism }\end{array}$ \\
\hline \multicolumn{4}{|l|}{ Soil type $\dagger$} \\
\hline Zarzal & $N=91$ & $N=57$ & nutrient and water availabil- \\
\hline Cristal & $N=29$ & $N=21$ & ity, tree community \\
\hline Others & $N=8$ & $N=8$ & \\
\hline
\end{tabular}

Notes: $\uparrow$ and $\$$ indicate that means and that coefficients of variation, respectively, were significantly different across land use intensity (see Appendix S1: Fig. S2 and Methods in main text). $N$ indicates the number of samples collected from a given soil type in high and low intensity of land use history.

abiotic variables (e.g., soil nitrogen) were not included to avoid collinearity among covariates. Specifically, total soil nitrogen and total soil carbon were highly correlated (Pearson correlation 0.93). Because soil types and soil $\mathrm{pH}$ captured variation in soil fertility, we decided to remove soil nitrogen from the analysis and keep soil carbon. Soil types were derived from the USDA Soil Survey, which classified the soil into five volcaniclastic types: Zarzal has low fertility, Cristal and Coloso low to moderate, Prieto moderate, and Fluvaquents moderate to high fertility (Soil Survey Staff 1995). The dominant soil types are Zarzal (148 samples), a deep and welldrained oxisol, and Cristal (50 samples), a deep but poorly drained ultisol. Prieto soils are moderately deep and poorly drained. Coloso and Fluvaquents soils are formed from alluvium in stream channels. Here, we considered Zarzal and Cristal soil types separately and created a third category by combining the three other soil types (16 soil samples; Coloso, 2; Prieto, 9; and Fluvaquents, 5), which had similar $\mathrm{pH}$ (Appendix S1: Fig. S3). In fall 2010 and spring 2011, we used a camera with a fisheye lens (Nikkor; Nikon, Tokyo, Japan) positioned at $1 \mathrm{~m}$ in height at the center of each seedling plot under uniform light conditions. The pictures were analyzed following the Ridler and Calvard (1978) algorithm, and we calculated gap light index (GLI), a metric of canopy openness and light availability. To quantify differences in soil water drainage, we estimated potential water flow using an elevation grid of the LFDP plot $(5 \times 5 \mathrm{~m})$ and the hydrology toolbox of ArcGIS (ESRI
2011). Soil $\mathrm{pH}$ was determined after 30 -min incubation in a $1: 1$ (weight fraction) soil: $\mathrm{H}_{2} 0$ solution. Total soil carbon was measured by combustion analysis (Elementar Vario Macro CNS Analyzer, Auburn University, Auburn, Alabama, USA). Soil iron concentration was measured using inductively coupled argon plasma (ICAP) spectroscopy. Since physical attributes of the forest might have influenced where land use occurred thereby confounding the effects of human activities on soil biota (Foster 1992), we included the percentage of rock present in each plot (reported as a categorical value binned by increments of 10 from 0 to 100) and the slope calculated at the $20 \times 20 \mathrm{~m}$ scale in the analyses.

We considered a number of biotic factors that could influence soil fungal community structure, including adult tree diversity, sum of basal tree area as a measure of aboveground plant biomass, and litterfall biomass (Table 1). Using the 2011 tree census, we calculated tree species diversity (Shannon index; Shannon and Weaver 1948) and the sum of basal tree area in a circle of $15 \mathrm{~m}$ radius around each seedling plot. Previous analyses in the LFDP (Uriarte et al. 2005) showed that a $15 \mathrm{~m}$ radius captured neighborhood interactions between individual trees, and exploratory analyses of the fungal data also showed that the strongest associations occur at this scale (unpublished data). We also estimated total annual litterfall biomass for each soil sample using models of leaf litter dispersal derived from tree plots data and litter falling into baskets for the 12 dominant tree species of the LFDP (Uriarte et al. 2015; Appendix S1: Table S1). 


\section{Soil fungal community analyses}

Soil samples were prepared for DNA sequencing, following Caporaso et al. (2012). Soil samples were thawed at room temperature, sieved, and extracted using the PowerSoil DNA isolation kit (MoBio, Carlsbad, California, USA). We extracted and then pooled three DNA extracts, using $3 \times 0.25 \mathrm{~g}$ of soil per sample, to determine the fungal community present in each sample. Fungi in the DNA extracts were sequenced using barcoded high-throughput sequencing on the Illumina MiSeq platform at the University of Colorado, Boulder, Colorado, USA, following McGuire et al. (2013). The first internal transcribed spacer region (ITS1) of the fungal rRNA gene was amplified using the modified primer pair ITS1-F (CTTGGTCATTTAGAGGAAG TAA) and ITS2 (GCTGCGTTCTTCATCGATG C; Bellemain et al. 2010). All DNA reads were demultiplexed, quality-filtered, and processed using the QIIME v. 1.5.0-dev pipeline with default settings except as noted (Caporaso et al. 2010). We used a 97\% similarity threshold to cluster sequences into operational taxonomic units (OTUs) using the open reference-based procedure in QIIME. For this, we used UCLUST (Edgar 2010) to cluster sequences with the UNITE November 2012 database (Abarenkov et al. 2010), and sequences that did not cluster with the database were clustered de novo. We excluded sequences less than $75 \%$ similar to any sequences in UNITE prior to OTU clustering as an additional quality control measure, assuming these sequences are artifacts or contaminants. Each sample was rarified to 500 sequences prior to downstream analyses. For taxonomic assignments, we used Basic Local Alignment Search Tool with the nucleotide database, excluding sequences not associated with known organisms, and the R package taxize (Chamberlain and Szöcs 2013) to extract the best taxonomy for each OTU from the GenBank taxonomic database (see Appendix $\mathrm{S} 1$ for details). We obtained fungal composition data for 214 soil samples (86 in low ILU and 128 in high ILU). For the analyses, we used the relative abundance of distinct OTUs defined as 97\% similar. Because the Illumina sequencing platform limits but does not fully eliminate PCR bias, relative OTU abundance should be interpreted as real abundance with caution (Lindahl et al. 2013). Fungal richness was calculated as the number of OTUs present in each plot, and fungal evenness was assessed using Pielou's index (Pielou 1966), which is calculated as Shannon diversity index/ln (species richness). A value close to 1 indicates that all fungal species have equal abundance and a value near 0 means that some fungal species have very high abundance whereas other species are rare.

\section{Statistical analysis}

(1) Do composition, richness, and evenness of soil fungal communities in a tropical forest differ between two areas with different intensities of historical human land use?

All composition analyses were performed using standardized Hellinger distance matrices to give less weight to rare phylotypes, which are often problematic in microbial community data (Legendre and Gallagher 2001). Due to this advantage, Hellinger transformation followed by Euclidean distances is commonly used in DNA type composition data analysis in microbiology (a few examples are Ramette 2007, Lekberg et al. 2012, Vasileiadis et al. 2013). To investigate how soil fungal composition differed with ILU, we first used PERMDISP analysis (Anderson 2006) to test for homogeneous dispersion in fungal community composition between ILU areas. This test enabled us to assess whether or not beta diversity was significantly different between high and low ILU, with higher dispersion indicating greater beta diversity. Preliminary analyses showed that fungal beta diversity was reduced in high relative to low ILU $\left(F_{1213}=12.1\right.$, $P$ value $<0.001)$. For this reason, we used permutational multivariate analysis of variance (PERMANOVA) that is more robust to dispersion effects (Anderson and Walsh 2013) to determine if soil fungal community composition differs with ILU. Significant results from PERMANOVA would suggest that soil fungal composition was different in high and low ILU due to both location and dispersion effects. In order to correct for differences in topography between ILU, we also incorporated the slope and the amount of rock as covariates. We then used non-metric multidimensional scaling (MDS; Kruskal 1964) for visual representation of the differences in fungal composition between soil samples.

Neither amount of rock nor slope had an effect on fungal richness or evenness (unpublished data); therefore we did not incorporate these covariates in any richness or evenness models but they were incorporated in analyses of composition. Wilcoxon rank-sum tests were used to compare how fungal phylum, class, order, and family richness and evenness differed between ILU. To account for the greater number of samples in high (128) relative to low (86) ILU, we bootstrapped the high ILU samples by randomly selecting 86 samples without replacement 100 times. The significance of the Wilcoxon test was corrected to account for multiple tests using the false discovery rate correction (FDR; Benjamini and Hochberg 1995). We used an analysis of variance (ANOVA) combined with bootstrapping as described above to assess the effect of land-use history on total fungal richness and evenness.

(2) Are the impacts of high and low ILU on soil fungal community composition, richness, and evenness explained by present-day variation in biotic or abiotic factors?

We used multivariate redundancy analyses (RDA; Legendre and Gallagher 2001) to investigate the importance of abiotic and biotic factors for fungal community composition (Table 1), while partitioning out the effects of rock and slope on fungal composition from the 
analyses to account for differences in topography between the two areas of ILU. We first checked for collinearity among covariates using Pearson correlation tests and found that only tree diversity and sum of basal tree area $15 \mathrm{~m}$ around seedling recruitment plots were slightly correlated $(r=0.38)$. We used backward and forward approaches for variable selection and variance inflation factors to investigate spurious correlation among explanatory variables (Legendre and Gallagher 2001).

To assess how abiotic and biotic factors affected soil fungal richness and evenness, we used linear regression followed by backward and forward approaches for variable selection. Covariates of the full model included the same nine variables used in the RDA. However, rock and topography were not included because these factors were not significantly correlated with fungal richness and evenness. Differences in sampling effort across ILU were addressed using bootstrapping followed by FDR correction as described above.

To correct for differences in sampling effort across soil types, we used 100 permutations of soil types across the 214 samples and the previously described RDA and linear regression to create distributions of $P$ values under random soil type associations. We compared the $P$ value of soil type obtained in the final RDA and linear models with these distributions. Soil type effect was considered significant if the $P$ value was lower than 0.05 and the 5\% quantile of the random $P$ value distributions (see Appendix S1: Table S2).

(3) Does the relative importance of abiotic and biotic factors in structuring soil fungal communities differ among areas with high and low ILU?

Prior to analyses, we tested for significant differences in abiotic and biotic factors between high and low ILU. To do so, we bootstrapped data from high ILU by randomly sampling 86 plots a thousand times and used $t$ tests to assess significant differences in average values and coefficients of variations of the selected abiotic and biotic factors. The significance of the $t$ tests was corrected to account for multiple tests using the FDR correction. Differences in abiotic and biotic factor values and coefficients of variation were then used to interpret differences in the relative importance of abiotic and biotic factors in structuring soil fungal communities among areas with high and low ILU. To assess how ILU altered the relative importance of abiotic and biotic factors in structuring the soil fungal communities, redundancy analyses were performed for each ILU dataset, using the variables retained in question (2). Significance of each variable was assessed using 1000 permutations. We used variance partitioning to determine the proportion of variance in the soil fungal community composition, richness, and evenness that was explained independently by abiotic factors (A), biotic factors (B), jointly by A and B, and unexplained in either ILU (Legendre 1993). The amount of variance jointly explained by abiotic and biotic factors can be interpreted as the variation explained by their indirect effects. Similarly, we separated soil fungal richness and evenness according to ILU and used a linear regression of fungal richness and evenness against the variables previously retained in question (2), followed by variance partitioning. Finally, we used chi-square test with 1000 Monte Carlo simulations to assess the significance of variance partitioning standardized by the total amount of explained variance between ILU for fungal composition, richness, and evenness.

Each covariate was $z$ transformed in order to allow comparison between effect sizes (Gelman and Hill 2007). Leaf litterfall biomass, soil carbon, and iron were first $\log$ transformed to correct for skewness. In all analyses, variance inflation factors were lower than 1.3 , indicating lack of collinearity among selected variables (Gross 2003). All analyses were performed in R 3.1.1 (R Core Team 2013) using the vegan package (Oksanen et al. 2013).

\section{Results}

We obtained fungal composition data for 214 soil samples. On average, there were 1791 successful reads per sample $(\min =606, \max =3737, \mathrm{SD}=551)$. After taxonomic identification, we found 7379 distinct OTUs, comprising seven phyla, 25 classes, 89 orders, and 231 families. There were 4957 OTUs found in high ILU and 3826 detected in low ILU. The most common fungal phyla were Ascomycota (4878 OTUs), Basidiomycota (1477 OTUs), and Glomeromycota (553 OTUs). The most abundant orders were Pezizales (1178 OTUs), Sordariales (1191 OTUs), Agaricales (769 OTUs), Glomerales (454 OTUs), Capnodiales (441 OTUs), and Polyporales (164 OTUs).

\section{Long lasting effects of land use on soil fungal communities}

Fungal community composition. - Comparison of dispersion in community composition between high and low ILU indicated that fungal beta diversity was significantly higher in low relative to high $\operatorname{ILU}\left(F_{3211}=12.1\right.$, $P<0.001)$. Consistent with our expectation, past land use intensity was a significant predictor of soil fungal community composition, explaining a small but significant difference in the composition of soil fungal communities (PERMANOVA, $F_{1213}=4.49, P=0.001$, $R^{2}=2.1 \%$; Fig. 2 and Table 2). At the phylum level, Basidiomycota and Glomeromycota were more abundant in high relative to low ILU, while Ascomycota and Chytridiomycota were more abundant in low compared to high ILU. At the class level, Agaricomyctes, Glomeromycetes, Tremellomycetes, Geoglossomycetes, Archaeorhizomycetes, Lecanoromycetes, and Schizosaccharomycetes were more abundant in high relative to low ILU. In contrast, Saccharomycetes, 


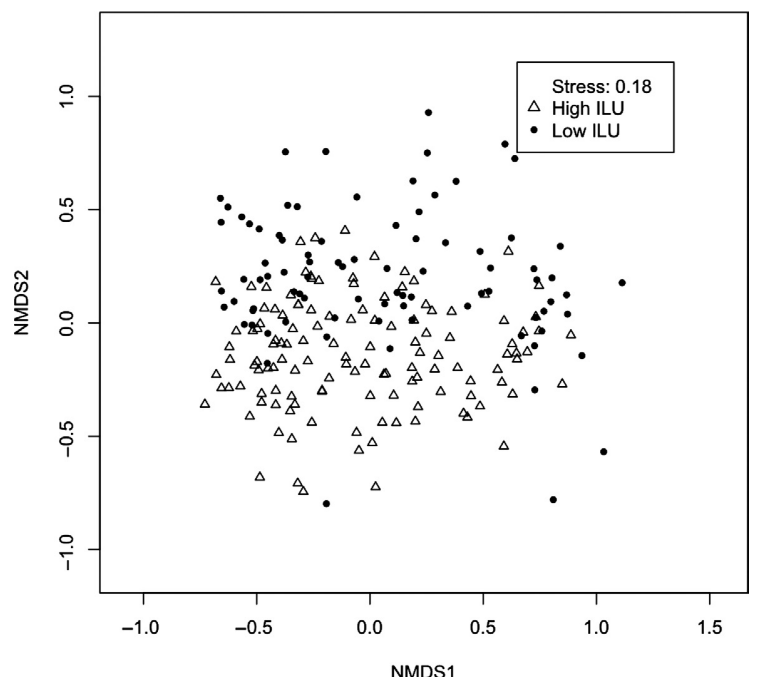

FIG. 2. Taxonomic composition of the low and high intensity of land use areas of the 16-ha LTER plot. Size of the bars represent the relative abundance of each of the dominant 16 orders recovered through Illumina sequencing using ITS-1F and ITS2 primers expressed as the relative number of OTUs. Together, these 16 orders capture about $90 \%$ of the total fungal OTU abundance. Letters in parentheses indicate the phylum: A, Ascomycota; B, Basidiomycota; G, Glomeromycota; and Z, Zygomycota.

Chytridiomycetes, Dothideomycetes, Leotiomycetes, Agaricostilbomycetes, and Archaeosporomycetes were more abundant in low compared to high ILU.

Fungal richness.-ILU was marginally negatively correlated with soil fungal richness $\left(P=0.07, R^{2}=2.3 \%\right.$; Table 2). Average OTU richness was highly variable among soil samples for all fungi (108 $\pm 25 \mathrm{SD}$ in high ILU, $97 \pm 30 \mathrm{SD}$ in low ILU). At lower taxonomic resolution, we detected significant effects of ILU: 30 out of 90 identified orders of fungi showed a significant difference in their OTU richness between high and low ILU and of these, all but five orders (Archaeosporales, Boletales, Peltigerales, Rhizophydiales, and Saccharomycetales) had greater fungal richness in high relative to low ILU (Fig. 3; Appendix S1: Table S3).

TABLE 2. Summary of the amount of variation in soil fungal community composition $\left(R^{2}\right.$ in \%), richness, and evenness captured by land use history as a categorical variable or by heterogeneity in biotic and abiotic factors.

\begin{tabular}{lcccc}
\hline Metric & $\begin{array}{c}\text { Land } \\
\text { use } \\
(\%)\end{array}$ & $\begin{array}{c}\text { Abiotic/ } \\
\text { biotic } \\
\text { factors } \\
(\%)\end{array}$ & $\begin{array}{c}\text { High } \\
\text { ILU (\%) }\end{array}$ & $\begin{array}{c}\text { Low } \\
\text { ILU (\%) }\end{array}$ \\
\hline Composition & 2.1 & 18.6 & 24.4 & 25.6 \\
Richness & 2.3 & 11.4 & 20.1 & 17.4 \\
Evenness & 6.7 & 10 & 3.5 & 10.7 \\
\hline
\end{tabular}

Note: We also show differences in the explanatory values of biotic and abiotic factors between the two land use types.
Fungal evenness. - Soil fungal evenness was high across the plot $($ mean $=0.73, \mathrm{SD}=0.11)$ and significantly higher in high ILU. ILU explained about $7 \%$ of the variance in the evenness of soil fungal communities $(P<0.001$; Table 2$)$. Thirteen out of 90 identified orders showed a difference in fungal evenness between high and low ILU; for all but two (Rhizophydiales and Saccharomycetales) orders, fungal abundance was more even in high relative to low ILU (Fig. 3; Appendix S1: Table S3).

\section{Correlation between fungal communities and abiotic and biotic factors}

Fungal community composition.-Soil fungal community composition was influenced by both biotic and abiotic factors. The final model retained seven variables, in order of importance: $\mathrm{pH}$, soil type, soil iron, canopy openness, total soil C, adult tree diversity, and total leaf litterfall biomass (Table 2). Altogether, these seven variables accounted for $18 \%$ of the variation in soil fungal community composition (RDA, pseudo- $F_{11203}=5.81$, $P=0.001$; Appendix S1: Table S4), with two variables, soil type and $\mathrm{pH}$, explaining most of the explained variation $(12 \%)$.

Fungal richness. - Biotic and abiotic factors, including soil type, tree diversity, soil $\mathrm{pH}$ and carbon, and potential water flow also influenced richness of soil fungal communities. These variables captured $12 \%$ of the variance in soil fungal richness (Table 2). Soil fungal richness was marginally higher in Cristal clay soils (intermediate fertility), positively associated with tree diversity and total soil carbon, and negatively associated with potential water flow and soil $\mathrm{pH}$ (Appendix S1: Table S5).

Fungal evenness.-Biotic and abiotic factors, namely soil type, tree diversity, and canopy openness, captured $10 \%$ of the variance in soil fungal evenness (Table 2). Soil fungal evenness was higher in Cristal clay soils (intermediate fertility) and was positively correlated with tree diversity and canopy openness (Appendix S1: Table S5).

\section{Relative importance of abiotic and biotic factors in structuring soil fungal communities in the two land use areas}

Abiotic and biotic factors differed between areas of low and high ILU.-Areas with high intensity of land use had lower average soil iron and carbon but higher $\mathrm{pH}$ than areas subject to low intensity of land use (Table 1; Appendix S1: Fig. S2). Additionally, soil carbon and iron were more homogeneous in high relative to low ILU (Table 1). Tree diversity, basal area, and canopy openness were also higher in areas of high ILU (Table 1; Appendix S1: Fig. S2). In contrast to soil metrics, adult tree diversity 


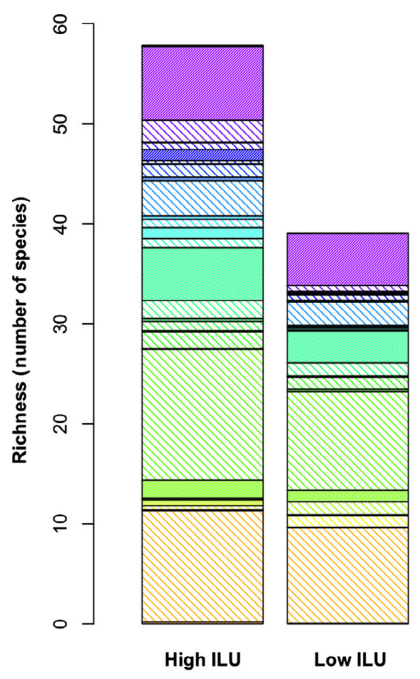

$\begin{array}{ll}\square \text { Acarosporales } & \text { (A) } \\ \text { Agaricales } & \text { (B) } \\ \square \text { Archaeorhizomycetales } & \text { (A) } \\ \square \text { Archaeosporales } & \text { (A) } \\ \square \text { Atheliales } & \text { (B) } \\ \text { Auriculariales } & \text { (B) } \\ \square \text { Boletales } & \text { (B) } \\ \square \text { Botryosphaeriales } & \text { (A) } \\ \square \text { Calosphaeriales } & \text { (A) } \\ \square \text { Chaetosphaeriales } & \text { (A) } \\ \square \text { Chaetothyriales } & \text { (A) } \\ \square \text { Coniochaetales } & \text { (A) } \\ \square \text { Corticiales } & \text { (B) } \\ \square \text { Dothideales } & \text { (A) } \\ \square \text { Geoglossales } & \text { (A) } \\ \square \text { Glomerales } & \text { (G) } \\ \square \text { Hypocreales } & \text { (A) } \\ \square \text { Lecanorales } & \text { (A) } \\ \square \text { Magnaporthales } & \text { (A) } \\ \square \text { Microascales } & \text { (A) } \\ \square \text { Mortierellales } & \text { (Z) } \\ \square \text { Peltigerales } & \text { (A) } \\ \square \text { Pezizales } & \text { (A) } \\ \square \text { Pleosporales } & \text { (A) } \\ \square \text { Rhizophydiales } & \text { (C) } \\ \square \text { Russulales } & \text { (B) } \\ \square \text { Saccharomycetales } & \text { (A) } \\ \square \text { Schizosaccharomycetales (A) } \\ \square \text { Sordariales } & \text { (A) } \\ \square \text { Trechisporales } & \text { (B) }\end{array}$
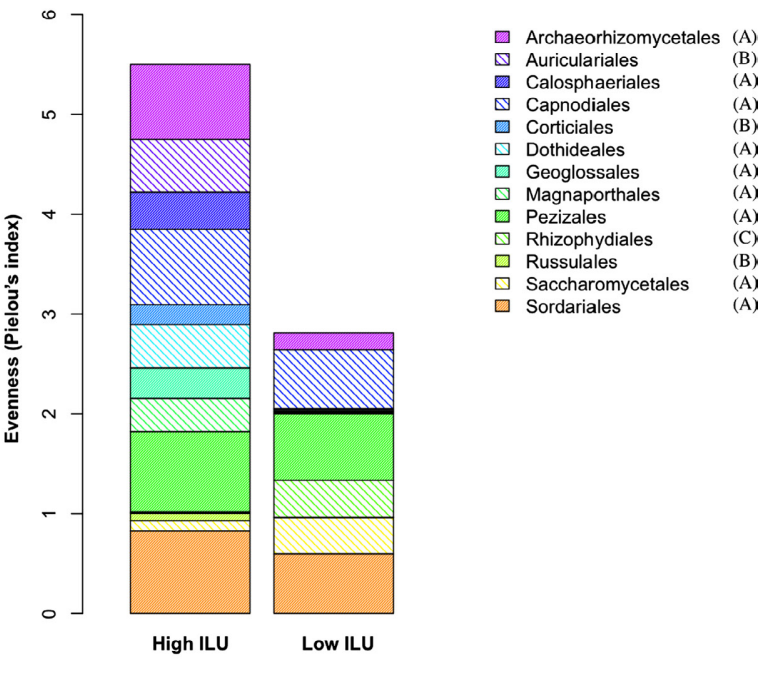

FIG. 3. Two-dimensional non-metric multidimensional scaling showing the difference in soil fungal composition (A, ANOSIM, global $r=0.17, P=0.001$ ) between low (circles) and high (triangles) intensity land use history.

and canopy openness were more homogeneous in low relative to high ILU (Table 1).

Fungal community composition.-As expected because of reduced heterogeneity in soil factors and greater functional tree diversity in high relative to low ILU, abiotic factors were more strongly correlated with soil fungal community composition in low ILU whereas biotic variables were more important in high ILU (chi-square test, $P=0.01$ ). In high ILU, soil iron, soil type, total carbon $\mathrm{C}$ and $\mathrm{pH}$, canopy openness, tree diversity, and leaf litter explained $20 \%$ of the observed variation in composition of the soil fungal community (RDA, pseudo- $F_{10204}=3.73, P=0.005$; Tables 2 and $3)$. Variance partitioning showed that $15 \%$ of the variation of soil fungal composition in high ILU was explained by abiotic factors with biotic factors accounting for only 3\% of the variation (Appendix S1: Fig. S4A). The remaining variance $(2 \%)$ was jointly explained by abiotic and biotic factors. In low ILU, iron, soil type and $\mathrm{pH}$, soil carbon, and leaf litter accounted for $26 \%$ of the variation in soil fungal community composition (RDA, pseudo- $F_{10204}=3.30$, $P=0.005$; Tables 2 and 3 ). As with high ILU, variance partitioning showed that the majority of observed variation $(22 \%)$ was captured by abiotic factors and only $3 \%$ by biotic factors (Appendix S1: Fig. S4A). The remaining variance $(1 \%)$ was jointly explained by abiotic and biotic factors.

Fungal richness. - Contrary to our expectation, abiotic factors were more strongly associated with soil fungal richness in high ILU, whereas biotic variables were more important in low ILU (chi-square test, $P<0.001$; Fig. 4). In high ILU, $18 \%$ of the observed variation in soil fungal richness was explained by soil type and soil carbon (Tables 2 and 4). Specifically, fungal richness increased with soil carbon and peaked in Cristal soil clays (intermediate fertility). Tree diversity captured $1 \%$ of the variation in fungal richness and the remaining 1\% was jointly captured by abiotic and biotic factors. In low ILU, 11\% of the observed variation in soil fungal richness was explained by soil $\mathrm{pH}$ and carbon, soil type, and potential water flow (Tables 2 and 4). Tree diversity captured 3.7\% of the variance in soil fungal richness (Tables 2 and 4).

Fungal evenness.-Contrary to our expectation, abiotic factors were more strongly associated with soil fungal richness in high ILU, whereas biotic variables were more important in low ILU (chi-square test, $P<0.001$; Fig. 4). In high ILU, fungal evenness peaked

TABLE 3. Results of the redundancy analysis for the soil fungal community composition across intensity of LU.

\begin{tabular}{lllllc}
\hline Factor & \multicolumn{2}{c}{ High ILU } & & \multicolumn{2}{c}{ Low ILU } \\
\cline { 2 - 3 } \cline { 5 - 6 } & $P$ value & $R^{2}(\%)$ & & $\begin{array}{c}P \\
\text { value }\end{array}$ & $\begin{array}{c}R^{2} \\
(\%)\end{array}$ \\
\hline $\begin{array}{l}\text { Canopy } \\
\quad \text { openness }\end{array}$ & 0.03 & 1.5 & & 0.25 & 1.2 \\
$\begin{array}{l}\text { Leaf litterfall } \\
\text { Soil C }\end{array}$ & 0.01 & 2.2 & & 0.03 & 1.9 \\
Soil pH & 0.03 & 1.0 & & 0.02 & 2.1 \\
$\begin{array}{l}\text { Soil type } \\
\text { Soil iron }\end{array}$ & 0.01 & 4.0 & & 0.01 & 6.5 \\
$\begin{array}{l}\text { Tree } \\
\quad \text { diversity }\end{array}$ & 0.01 & 4.5 & & 0.01 & 7.5 \\
& & 5.6 & & 0.01 & 5.4 \\
\end{tabular}

Note: Empty cells indicate that tree diversity was not retained in the high ILU model. 
Abiotic $\mathbb{H}_{\mathrm{I}}$ Biotic $\square$ Abiotic $\times$ biotic
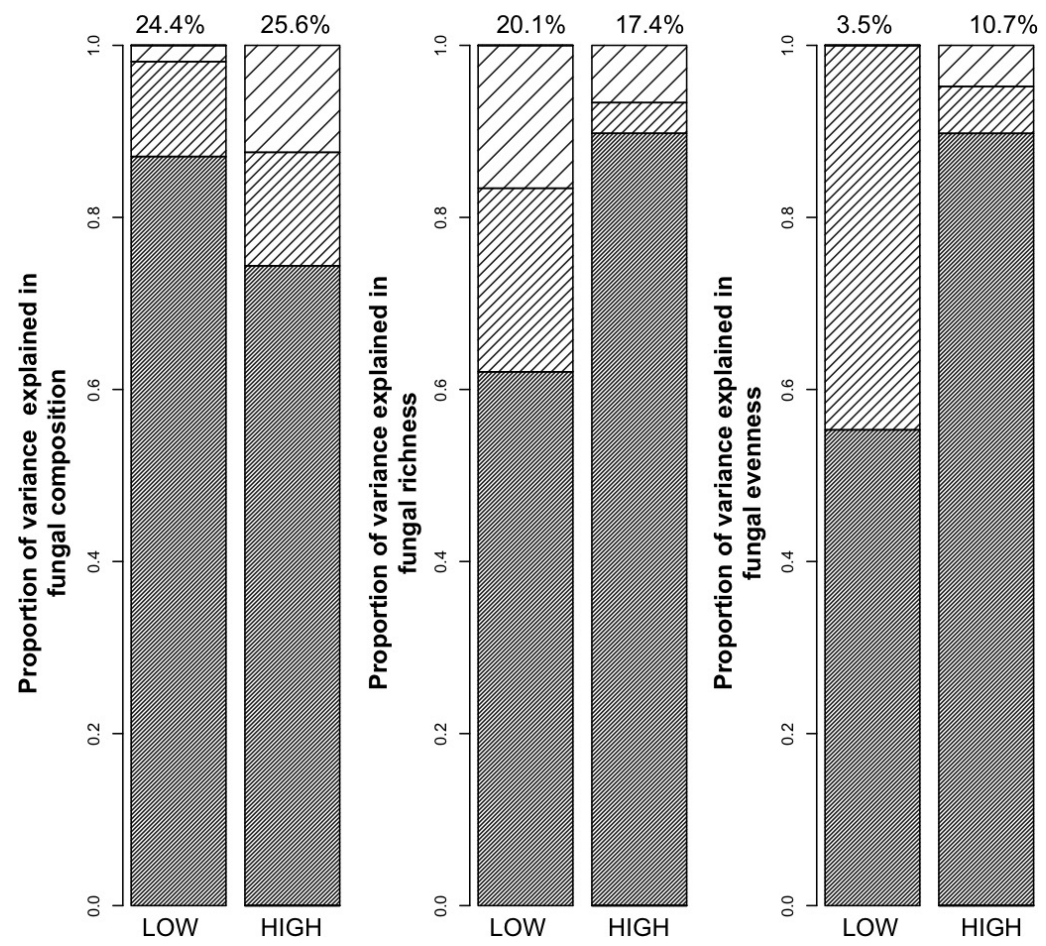

FIG. 4. Variance partitioning among abiotic (dark gray bars), biotic (narrow-hashed) factors, and their intersection (wide-hashed) that structure the community composition, richness, and evenness of soil fungi in low and high ILU. Total $R^{2}$ is indicated above each bar $(\%)$.

in Cristal soil and this effect explained $3 \%$ of the variance in fungal evenness (Tables 2 and 4). In low ILU, tree diversity was the only variable significantly correlated with fungal evenness and it explained $5 \%$ of the variance in evenness of soil fungal communities (Tables 2 and 4).

\section{Discussion}

Land use is an important global driver of change in biotic communities (Sala et al. 2000), including communities of belowground organisms (Anderson 1995). Intense land use is often associated with changes in soil

TABLE 4. Mean and SE for standardized parameters of the regression models for soil fungal richness and evenness in high and low ILU.

\begin{tabular}{|c|c|c|c|c|c|c|c|c|c|}
\hline \multirow[b]{2}{*}{ Model } & \multirow[b]{2}{*}{ Factor } & \multicolumn{4}{|c|}{ High ILU } & \multicolumn{4}{|c|}{ Low ILU } \\
\hline & & Estimate & SE & $\begin{array}{c}P \\
\text { value }\end{array}$ & $R^{2}(\%)$ & Estimate & $\mathrm{SE}$ & $P$ value & $R^{2}(\%)$ \\
\hline \multirow[t]{6}{*}{ Richness } & Soil C & 0.37 & 0.1 & $<0.001$ & 8.8 & 0.1 & 0.1 & 0.27 & 1.3 \\
\hline & Soil pH & -0.1 & 0.08 & 0.22 & 1 & -0.29 & 0.12 & 0.02 & 6.4 \\
\hline & Soil type: Cristal & 0.95 & 0.4 & 0.02 & 9 & 0.46 & 0.42 & 0.27 & 1.4 \\
\hline & Soil type: other & 0.59 & 0.2 & 0.004 & & 0.14 & 0.25 & 0.58 & \\
\hline & Tree diversity & 0.09 & 0.09 & 0.32 & 0.7 & 0.21 & 0.11 & 0.06 & 3.7 \\
\hline & Water flow & -0.08 & 0.09 & 0.33 & 0.6 & -0.21 & 0.13 & 0.1 & 2.9 \\
\hline \multirow[t]{4}{*}{ Evenness } & Canopy openness & 0.05 & 0.09 & 0.57 & 0.2 & 0.23 & 0.13 & 0.08 & 3.3 \\
\hline & Soil type: Cristal & 0.22 & 0.37 & 0.56 & 3 & 0.34 & 0.38 & 0.37 & 2.4 \\
\hline & Soil type: other & 0.42 & 0.22 & 0.06 & & 0.33 & 0.25 & 0.19 & \\
\hline & Tree diversity & 0.05 & 0.1 & 0.62 & 0.2 & 0.22 & 0.1 & 0.03 & 5 \\
\hline
\end{tabular}

Note: Intercepts for Cristal and other soil type represent the average differences in soil fungal richness in Cristal and other soils relative to Zarzal soils. 
fungal communities (Bardgett 2005), and these effects can persist long after land use has ceased (Brussaard 1997). The distribution of land use, however, is not random on landscapes and areas of the LFDP that were steeper and rockier only experienced light logging. After accounting for these non-random differences, our results show long-lasting effects of land use history on the composition, richness, and evenness of soil fungal communities. Soil characteristics, canopy openness, and tree diversity were the main factors associated with variation in soil fungal community composition, richness, and evenness. Furthermore, we detected differences in the relative importance of abiotic and biotic variables in structuring soil fungal richness, evenness, and composition between areas subject to different intensities of historical land use. Across the study site, abiotic factors were the major drivers of soil fungal community composition, richness, and evenness, particularly in areas with low intensity land use. In contrast, biotic factors had greater explanatory power for fungal richness and evenness in low than in high ILU.

\section{Long-lasting effects of land use on soil fungal communities}

Fungal community composition revealed a significant land use signature 80 years after abandonment of farming and logging. This substantiates the hypothesis that land use legacies may affect ecosystems for decades (Foster et al. 2003, Martiny et al. 2006), including soil fungi (Hartmann et al. 2012, McGuire et al. 2015). Specifically, this result supports other studies demonstrating effects of land use on arbuscular mycorrhizal fungi (Öpik et al. 2006, Tchabi et al. 2008) and soil decomposers (Carlile et al. 2001) in agroforestry and savannah tropical ecosystems. Our data indicated that soil fungal beta diversity is reduced in areas that were previously farmed and logged, suggesting that fungal composition in these areas exhibits lower turnover between plots relative to areas that underwent light logging (Whittaker 1960). Lower turnover in high relative to low ILU could arise from different processes (Legendre et al. 2005). First, areas of high ILU might be dominated by a suite of competitive fungal species that have been favored by farming and logging. Second, fungal species in high ILU might be less dispersal limited than in low ILU. This might be the case if ruderal species have been favored in areas of high ILU. Finally, beta diversity might be lower in high ILU due to more homogeneous environmental conditions.

We found that the richness of soil fungal communities was similar among areas with different land use legacies but that evenness was highest in areas with historical farming and logging. Previous studies of the effects of land use on soil fungi typically compared forests and pastures or fields and often detected reduction in fungal richness in disturbed areas (Carpenter et al. 2001, Kulmatiski and Beard 2008). Discrepancies between our results and previous studies could arise because our site contains old-growth and well-developed second-growth forests (80-yr old), where differences in vegetation are less marked, explaining similar fungal richness in low and high ILU. Furthermore, results from other studies on the effects of on-going land use on indices of soil fungal richness are mixed (Guadarrama and Álvarez-Sánchez 1999, Carpenter et al. 2001, Kulmatiski and Beard 2008, Violi et al. 2008, Vályi et al. 2015). This disparity could arise from variation in the index of diversity used. Our results show that species evenness responds to previous land use intensity more than species richness, as previously suggested by Chapin et al. (2000). Although we found no association between historical land use and fungal richness, there was greater community evenness in high ILU areas. This pattern could reflect differences in heterogeneity between ILU. Greater evenness in soil fungal communities in high ILU could arise from high heterogeneity in tree communities. In contrast, there is lower tree diversity in low ILU, which could favor dominance of a few fungal types, thereby reducing fungal evenness.

\section{Association between fungal communities and abiotic and biotic factors}

Several abiotic and biotic factors were associated with soil fungal community composition. Overall, we found that soil properties (soil types, soil nutrients, and soil $\mathrm{pH}$ ) were correlated with fungal community composition, which confirms recent findings at the global scale (Fierer et al. 2009, Tedersoo et al. 2014). Consistent with previous studies (Garbeva et al. 2004, Lauber et al. 2008, Berg and Smalla 2009, Peay et al. 2013), we found that soil type was correlated with soil fungal community composition, richness, and evenness. Soil type represents variation in soil characteristics at broad scales, encompassing a range of soil fertility across which different fungal species might be favored. Soil fungal community composition and evenness also responded to variation in $\mathrm{pH}$. This is consistent with the idea that $\mathrm{pH}$ has species-specific effects on fungal metabolism (Oehl et al. 2010, Tedersoo et al. 2014). Our findings support another study showing strong positive correlation between indexes of fungal diversity and $\mathrm{pH}$ ranging from 3.2 to 7 (Bååth and Anderson 2003, but see Rousk et al. 2010). The discrepancies among our results and those from other studies could arise from methodological differences or from non-linear effects of $\mathrm{pH}$ on soil fungal communities (Shi et al. 2013). We also found an association between soil fungal community composition and soil iron, which could be due to the biochemical uses of iron in fungi. Many saprotrophic fungi require iron to decompose wood because it stimulates decomposition via formation of hydroxyl radicals (Hall and Silver 2013). Soil fungal community composition was also associated with total soil $\mathrm{C}$ and amount of leaf litterfall, which might occur when soil fungal decomposers are 
carbon limited (Chapin et al. 2011). Finally, canopy openness and potential water flow were associated with soil fungal community composition consistent with the fact that both canopy openness and potential water flow alter litter decomposition rates (Gholz et al. 2000, DeAngelis et al. 2013) and enhance fungal development and spread because water is important for spore dispersal (Agrios 2005).

Our study supports the existence of linkages between plant and belowground fungal communities (Peay et al. 2013, Mueller et al. 2014, Barberán et al. 2015, MartínezGarcía et al. 2015, Urbanová et al. 2015). Although the correlation between soil fungal richness, evenness, and composition and biotic factors was not as strong as the associations with abiotic factors, consistent with previous research (Wagg et al. 2015), soil fungal richness and evenness increased with tree diversity, suggesting some degree of host-preference between fungi and plants (Toju et al. 2013). For instance, fungal decomposer communities may be associated with particular tree species (Prescott and Grayston 2013), just as pathogenic and mycorrhizal fungi exhibit host-preferences (Toju et al. 2013, Tedersoo et al. 2014).

\section{Shifts in the importance of abiotic and biotic factors in structuring soil fungal community composition, richness, and evenness across areas with differing land use intensities}

Although abiotic factors were the main driver of variation in soil fungal community composition across the study plot, the importance of biotic factors differed between areas with differing land use history. Biotic factors shaped the composition of soil fungal communities more strongly in areas of high relative to low ILU, suggesting that biotic heterogeneity drives fungal community composition more strongly in areas of high than low ILU. In contrast, biotic factors shaped the richness and evenness of soil fungal communities more strongly in areas of low relative to high ILU, suggesting that biotic factors are more important in areas of low than high ILU.

The greater importance of biotic factors in shaping fungal composition in high compared to low ILU was associated with tree diversity. This might arise because of greater functional trait diversity in the high ILU area of the LFDP (Swenson et al. 2012), and possibly, the higher functional diversity of tree hosts. The lower contribution of abiotic factors to soil fungi composition in these areas may arise from a more homogeneous soil abiotic environment in high ILU. The facts that several soil factors, such as soil iron and soil carbon, showed reduced heterogeneity in high relative to low ILU areas (Table 1) support this notion.

Biotic factors captured more of the explained variation in both richness and evenness in areas subject to low historical land use that have low functional tree diversity than in high ILU areas. In contrast, edaphic factors were more important in areas subject to farming and logging where soils are more homogeneous but canopy openness is more heterogeneous than in low ILU areas. Richness and evenness metrics, which reduce a very heterogeneous fungal community of pathogens, saprotrophs, lichens, and mutualists to a single number, might represent a mean response of the fungal communities to abiotic and biotic factors. Therefore, as a factor becomes more heterogeneous, the strength of its association with fungal biodiversity metrics might decrease.

Tree diversity was positively correlated with fungal evenness and richness. However, in area of high ILU where tree diversity is more heterogeneous, fungal evenness and richness were not significantly correlated with tree diversity. Therefore, this might explain why the importance of biotic factor was stronger in low relative to high ILU. Alternatively, biotic linkages might be tighter in old-growth forests where the lack of human disturbances might have enabled tree and fungal species to interact for longer ecological times and to develop strong above and belowground linkages (Peay et al. 2013). The main driver of fungal richness in high ILU was soil total carbon. However, in areas of low ILU, this factor was not significantly correlated with fungal richness. As previously discussed, this loss of significant correlation could be the results of greater heterogeneity in soil total carbon in low ILU. Alternatively, soil total carbon was significantly lower in areas of high ILU and therefore could be a limiting factor for soil fungi. Therefore, the tight correlation between fungal richness and soil total carbon might suggest carbon limitation in areas of high ILU.

Our study demonstrates long-lasting effects of historical land use on soil fungal community composition, richness, and evenness, which might influence tropical forest functioning, highlighting the need for additional studies in second growth tropical forests. We found evidence that areas subject to farming and logging hosted a more even soil fungal community than areas subject to light logging and that these differences might reflect changes in environmental factors and limiting conditions or spatial homogeneity in biotic and abiotic factors. Such differences in soil fungal communities could result in changes in their functional roles. Fungi are key actors in nutrient cycling by decomposing organic matter, retaining, and providing nutrients to plants (Lodge 1991, Waring et al. 2016). Change in these functions could lead to less or more fertile tropical forest floors. Fungi are also important plant pathogens and mutualists that are key actors to maintain high tropical tree diversity (Bagchi et al. 2014, Bachelot 2015, Liang et al. 2015). Therefore, change in fungal communities could not only impact forest floors but also the overall diversity of tropical forests. Future studies should develop more tools to measure changes in functional diversity and investigate these changes are associated with variation in fungal community composition. Most of the variation in fungal communities was 
unexplained by our factor, suggesting that fungi might by randomly structured (Lekberg et al. 2012). However, our study emphasizes the important role of soil and biotic heterogeneity in structuring soil fungal communities, indicating that fungal assemblages might also reflect environmental niches.

\section{ACKNOWLEDGMENTS}

This work was supported by grants from the Institute of Latin American Studies at Columbia University to M. Uriarte, K. McGuire, and B. Bachelot; from Columbia University to B. Bachelot; and grants BSR-8811902, DEB 9411973, DEB 0080538, DEB 0218039, DEB 0620910 and DEB 0963447 from NSF to the Institute for Tropical Ecosystem Studies, University of Puerto Rico, and to the International Institute of Tropical Forestry USDA Forest Service for the Luquillo LTER program. We thank the LTER volunteers who helped with tree censuses and two anonymous reviewers for useful comments.

\section{Literature Cited}

Abarenkov, K., R. et al. 2010. The UNITE database for molecular identification of fungi: recent updates and future perspectives. New Phytologist 186:281-285.

Agrios, G. N. 2005. Plant pathology, Fifth edition. Academic Press, New York, New York, USA.

Anderson, J. M. 1995. The soil system. Pages 406-412 in H. A. Mooney, J. Lubchenco, R. Dirzo and O. E. Sala, editors. Global biodiversity assessment. Cambridge University Press, Cambridge, UK.

Anderson, M. J. 2005. Global biodiversity assessment. Cambridge University Press, Cambridge, UK. Pages 406-412.

Anderson, M. J. 2006. Distance-based tests for homogeneity of multivariate dispersions. Biometrics 62:245-253.

Anderson, M. J., and D. C. I. Walsh. 2013. PERMANOVA, ANOSIM, and the Mantel test in the face of heterogeneous dispersions: What null hypothesis are you testing? Ecological Monographs 83:557-574.

Bachelot, B., 2015. The role of arbuscular mycorrhizal fungi, and natural enemy communities on seedling dynamics in a secondary tropical rain forest. Dissertation. Columbia University, New York, New York, USA.

Bagchi, R., R. E. Gallery, S. Gripenberg, S. J. Gurr, L. Narayan, C. E. Addis, R. P. Freckleton, and O. T. Lewis. 2014. Pathogens and insect herbivores drive rainforest plant diversity and composition. Nature 506:85-88.

Barberán, A., K. L. McGuire, J. A. Wolf, F. A. Jones, S. J. Wright, B. L. Turner, A. Essene, S. P. Hubbell, B. C. Faircloth, and N. Fierer. 2015. Relating belowground microbial composition to the taxonomic, phylogenetic, and functional trait distributions of trees in a tropical forest. Ecology Letters 18:1397-1405.

Bardgett, R. D. 2005. The biology of soil: a community and ecosystem approach, First edition. Oxford University Press, Oxford, UK.

Bellemain, E., T. Carlsen, C. Brochmann, E. Coissac, P. Taberlet, and H. Kauserud. 2010. ITS as an environmental DNA barcode for fungi: an in silico approach reveals potential PCR biases. BMC Microbiology 10:189.

Benjamini, Y., and Y. Hochberg. 1995. Controlling the false discovery rate: a practical and powerful approach to multiple testing. Journal of the Royal Statistical Society B 57:289-300.
Berg, G., and K. Smalla. 2009. Plant species and soil type cooperatively shape the structure and function of microbial communities in the rhizosphere. FEMS Microbiology Ecology 68:1-13.

Brussaard, L. 1997. Biodiversity and ecosystem functioning in soil. Ambio 26:563-570.

Caporaso, J. G., J. Kuczynski, and J. Stombaugh. 2010. QIIME allows analysis of high-throughput community sequencing data. Nature Methods 7:335-336.

Caporaso, J. G., et al. 2012. Ultra-high-throughput microbial community analysis on the Illumina HiSeq and MiSeq platforms. ISME Journal 6:1621-1624.

Carlile, M. J., S. C. Watkinson, and G. W. Gooday. 2001. The fungi. Academic Press, San Diego, California, USA.

Carpenter, F. L., S. P. Mayorga, E. G. Quintero, and M. Schroeder. 2001. Land-use and erosion of a Costa Rican Ultisol affect soil chemistry, mycorrhizal fungi and early regeneration. Forest Ecology and Management 144:1-17.

Chamberlain, S. A., and E. Szöcs. 2013. taxize: taxonomic search and retrieval in R. F1000Research 191:1-28.

Chapin, F. S. III, et al. 2000. Consequences of changing biodiversity. Nature 405:234-242.

Chapin, F. S. III, M. C. Chapin, P. A. Matson, and P. Vitousek. 2011. Principles of terrestrial ecosystem ecology. Springer, New York, USA.

Chazdon, R. L. 2003. Tropical forest recovery: legacies of human impact and natural disturbances. Perspectives in Plant Ecology, Evolution and Systematics 6:51-71.

Clemmensen, K. E., R. D. Finlay, A. Dahlberg, J. Stenlid, D. A. Wardle, and B. D. Lindahl. 2015. Carbon sequestration is related to mycorrhizal fungal community shifts during long-term succession in boreal forests. New Phytologist 205:1525-1536.

Coleman, D. C., and J. D. A. Crossley. 1996. Fundamentals of soil ecology. Academic Press, San Diego, California, USA.

DeAngelis, K. M., D. Chivian, J. L. Fortney, A. P. Arkin, B. Simmons, T. C. Hazen, et al. 2013. Changes in microbial dynamics during long-term decomposition in tropical forests. Soil Biology and Biochemistry 66:60-68.

Dickie, I. A., et al. 2015. Evolving insights to understanding mycorrhizas. New Phytologist 205:1369-1374.

Edgar, R. C. 2010. Search and clustering orders of magnitude faster than BLAST. Bioinformatics 26:2460-2461.

ESRI. 2011. ArcGIS desktop: release 10. Environmental Systems Research Institute (ESRI), Redlands, California, USA.

FAO. 2010. Global Forest Resources Assessment 2010. Food and Agriculture Organization (FAO) of the United Nations, Rome, Italy.

Ferrer, A., and G. S. Gilbert. 2003. Effect of tree host species on fungal community composition in a tropical rain forest in Panama. Diversity and Distributions 9:455-468.

Fierer, N., and R. B. Jackson. 2006. The diversity and biogeography of soil bacterial communities. Proceedings of the National Academy of Sciences USA 103:626-631.

Fierer, N., M. S. Strickland, D. Liptzin, M. A. Bradford, and C. C. Cleveland. 2009. Global patterns in belowground communities. Ecology Letters 12:1238-1249.

Flinn, K. M., and P. L. Marks. 2007. Agricultural legacies in forest environments: tree communities, soil properties, and light availability. Ecological Applications 17:452-463.

Foster, D. R. 1992. Land-use history (1730-1990) and vegetation dynamics in central New England, USA 754 Land use and vegetation history in New England. Journal of Ecology 80:753-771. 
Foster, D., et al. 2003. The importance of land-use legacies to ecology and conservation. BioScience 53:77-88.

Fraterrigo, J., and M. Turner. 2005. Effects of past land use on spatial heterogeneity of soil nutrients in southern Appalachian forests. Ecological Monographs 75:215-230.

Frey, S. D., M. Knorr, J. L. Parrent, and R. T. Simpson. 2004. Chronic nitrogen enrichment affects the structure and function of the soil microbial community in temperate hardwood and pine forests. Forest Ecology and Management 196:159-171.

Garbeva, P., J. A. van Veen, and J. D. van Elsas. 2004. Microbial diversity in soil: selection microbial populations by plant and soil type and implications for disease suppressiveness. Annual Review of Phytopathology 42:243-270.

Gelman, A., and J. Hill. 2007. Data analysis using regression and multilevel/hierarchical models. Cambridge University Press, Cambridge, UK.

Gholz, H. L., D. A. Wedin, S. M. Smitherman, M. E. Harmon, and W. J. Parton. 2000. Long-term dynamics of pine and hardwood litter in contrasting environments: toward a global model of decomposition. Global Change Biology 6:751-765.

Glinka, C., and C. V. Hawkes. 2014. Environmental controls on fungal community composition and abundance over 3 years in native and degraded shrublands. Microbial Ecology 68:807-817.

de Graaff, M. A., A. T. Classen, H. F. Castro, and C. W. Schadt. 2010. Labile soil carbon inputs mediate the soil microbial community composition and plant residue decomposition rates. New Phytologist 188:1055-1064.

Grman, E., J. L. Orrock, C. W. Habeck, J. A. Ledvina, and L. A. Brudvig. 2015. Altered beta diversity in postagricultural woodlands: two hypotheses and the role of scale. Ecography 38:614-621.

Gross, J. 2003. Variance inflation factors. R News 3:13-15.

Guadarrama, P., and F. Álvarez-Sánchez. 1999. Abundance of arbuscular mycorrhizal fungi spores in different environments in a tropical rain forest, Veracruz, Mexico. Mycorrhiza 8:267-270.

Guariguata, M. R., and R. Ostertag. 2001. Neotropical secondgrowth forest succession: changes in structural and functional characteristics. Forest Ecology and Management 148:185-206.

Hall, S. J., and W. L. Silver. 2013. Iron oxidation stimulates organic matter decomposition in humid tropical forest soils. Global Change Biology 19:2804-2813.

Hartmann, M., C. G. Howes, D. VanInsberghe, H. Yu, D. Bachar, R. Christen, R. Henrik Nilsson, S. J. Hallam, and W. W. Mohn. 2012. Significant and persistent impact of timber harvesting on soil microbial communities in Northern coniferous forests. The ISME Journal 6:2199-2218.

Husband, R., E. A. Herre, S. L. Turner, R. Gallery, and J. P. W. Young. 2002a. Molecular diversity of arbuscular mycorrhizal fungi and patterns of host association over time and space in a tropical forest. Molecular Ecology 11:2669-2678.

Husband, R., E. A. Herre, and J. P. W. Young. 2002b. Temporal variation in the arbuscular mycorrhizal communities colonising seedlings in a tropical forest. FEMS Microbiology Ecology 42:131-136.

Klironomos, J. N., M. C. Rillig, and M. F. Allen. 1999. Designing belowground field experiments with the help of semi-variance and power analyses. Applied Soil Ecology $12: 227-238$
Kruskal, J. 1964. Multidimensional scaling by optimizing goodness of fit to a nonmetric hypothesis. Psychometrika 29:1-27.

Kulmatiski, A., and K. Beard. 2008. Plant-soil feedbacks: a meta-analytical review. Ecology Letters 11:980-992.

Lauber, C. L., M. S. Strickland, M. A. Bradford, and N. Fierer. 2008. The influence of soil properties on the structure of bacterial and fungal communities across land-use types. Soil Biology and Biochemistry 40:2407-2415.

Legendre, P. 1993. Spatial autocorrelation: trouble or new paradigm? Ecology 74:1659-1673.

Legendre, P., and E. D. Gallagher. 2001. Ecologically meaningful transformations for ordination of species data. Oecologia 129:271-280.

Legendre, P., D. Borcard, P. Couteron, P. R. Peres-Neto, H. Tuomisto, K. Ruokolainen, R. Pelissier, S. Dray, and E. Laliberté. 2005. Analyzing beta diversity: partitioning the spatial variation of community composition data. Ecological Monographs 75:435-450.

Leigh, J., A. Hodge, and A. H. Fitter. 2009. Arbuscular mycorrhizal fungi can transfer substantial amounts of nitrogen to their host plant from organic material. New Phytologist 181:199-207.

Lekberg, Y., T. Schnoor, R. Kjøller, S. M. Gibbons, L. H. Hansen, W. A. Al-Soud, S. J. Sørensen, and S. Rosendahl. 2012. 454-sequencing reveals stochastic local reassembly and high disturbance tolerance within arbuscular mycorrhizal fungal communities. Journal of Ecology 100:151-160.

Li, X., and P. Christie. 2001. Changes in soil solution $\mathrm{Zn}$ and $\mathrm{pH}$ and uptake of $\mathrm{Zn}$ by arbuscular mycorrhizal red clover in Zn-contaminated soil. Chemosphere 42:201-207.

Liang, M. I. L., X. U. L. Iu, R. A. S. E. Tienne, F. E. H. Uang, and Y. O. W. Ang. 2015. Arbuscular mycorrhizal fungi counteract the Janzen-Connell effect of soil pathogens. Ecology 96:562-574.

Lindahl, B. D., R. H. Nilsson, L. Tedersoo, K. Abarenkov, T. Carlsen, R. Kjøller, U. K. Oljalg, T. Pennanen, S. Rosendahl, J. Stenlid, and H. Kauserud. 2013. Methods Fungal community analysis by high-throughput sequencing of amplified markers - a user's guide. New Phytologist 199:288-299.

Lodge, D. J. 1991. Nutrient cycling by fungi in wet tropical forests. Page 37 in British Mycological Society Symposium Series 1993, Volume 19. Cambridge University Press, Cambridge, UK.

Lodge, D. J. 1997. Factors related to diversity of decomposer fungi in tropical forests. Biodiversity \& Conservation 6:681-688.

Lovelock, C. E., and J. J. Ewel. 2005. Links between tree species, symbiotic fungal diversity and ecosystem functioning in simplified tropical ecosystems. New Phytologist 167:219-228

Marín-Spiotta, E., D. F. Cusack, R. Ostertag, and W. L. Silver. 2008. Trends in above and belowground carbon with forest regrowth after agricultural abandonment in the neotropics. In Post-agricultural succession in the neotropics. Springer, pp. 22-72, Springer, New York, USA.

Martínez-García, L. B., S. J. Richardson, J. M. Tylianakis, D. A. Peltzer, and I. A. Dickie. 2015. Host identity is a dominant driver of mycorrhizal fungal community composition during ecosystem development. New Phytologist 205:1565-1576.

Martiny, J. B. H., et al. 2006. Microbial biogeography: putting microorganisms on the map. Nature Reviews Microbiology 4:102-112. 
McGuire, K., N. Fierer, C. Bateman, K. Treseder, and B Turner. 2011. Fungal community composition in neotropical rain forests: the influence of tree diversity and precipitation. Microbial Ecology 63:804-812.

McGuire, K. L., et al. 2013. Digging the New York City skyline: soil fungal communities in green roofs and city parks. PLoS ONE 8:e58020.

McGuire, K. L., et al. 2015. Responses of soil fungi to logging and oil palm agriculture in Southeast Asian tropical forests. Microbial Ecology 69:733-747.

Moora, M., et al. 2014. Anthropogenic land use shapes the composition and phylogenetic structure of soil arbuscular mycorrhizal fungal communities. FEMS Microbiology Ecology 90:609-621.

Mueller, R. C., F. S. Paula, B. S. Mirza, J. L. M. Rodrigues, K. Nüsslein, and B. J. M. Bohannan. 2014. Links between plant and fungal communities across a deforestation chronosequence in the Amazon rainforest. ISME Journal 8:1548-1550.

Oehl, F., et al. 2010. Soil type and land use intensity determine the composition of arbuscular mycorrhizal fungal communities. Soil Biology and Biochemistry 42: 724-738.

Ohsowski, B., P. Zaitsoff, M. Öpik, and M. Hart. 2014. Where the wild things are: looking for uncultured Glomeromycota. New Phytologist 204:171-179.

Oksanen, J., J. R. Kindt, P. Legendre, B. O'Hara, M. Henry, and H. Stevens. 2013. The vegan package. Community ecology package 10 .

Öpik, M., M. Moora, J. Liira, and M. Zobel. 2006. Composition of root-colonizing arbuscular mycorrhizal fungal communities in different ecosystems around the globe. Journal of Ecology 94:778-790.

Öpik, M., A. Vanatoa, E. Vanatoa, M. Moora, J. Davison, J. M. Kalwij, Ü. Reier, and M. Zobel. 2010. The online database MaarjAM reveals global and ecosystemic distribution patterns in arbuscular mycorrhizal fungi (Glomeromycota). New Phytologist 188:223-241.

Peay, K. G., C. Baraloto, and P. V. A. Fine. 2013. Strong coupling of plant and fungal community structure across western Amazonian rainforests. ISME Journal $7: 1852-1861$.

Pielou, E. C. 1966. The measurement of diversity in different types of biological collection. Journal of Theoretical Biology 13:131-144

Prescott, C. E., and S. J. Grayston. 2013. Tree species influence on microbial communities in litter and soil: current knowledge and research needs. Forest Ecology and Management 309:19-27.

Prusky, D., and N. Yakoby. 2003. Pathogenic fungi: leading or led by ambient $\mathrm{pH}$ ? Molecular Plant Pathology 4:509-516.

R Core Team. 2013. R: a language and environment for statistical computing. $\mathrm{R}$ Foundation for Statistical Computing, Vienna, Austria. www.r-project.org

Ramette, A. 2007. Multivariate analyses in microbial ecology FEMS Microbiology Ecology 62:142-160.

Ridler, T., and S. Calvard. 1978. Picture thresholding using and iterative selection method. IEEE Transactions on Systems, Man, and Cybernetics 8:630-632.

Rousk, J., E. Baath, P. C. Brookes, C. L. Lauber, C. Lozupone, J. G. Caporaso, R. Knight, and N. Fierer. 2010. Soil bacterial and fungal communities across a $\mathrm{pH}$ gradient in an arable soil. ISME Journal 4:1340-1351.

Sala, O. E., et al. 2000. Global biodiversity scenarios for the year 2100. Science 287:1770-1774.
Shannon, C. E., and W. Weaver. 1948. A mathematical theory of communication. Bell Technical Journal 27:379-423.

Shi, L. L., et al. 2013. Variation in forest soil fungal diversity along a latitudinal gradient. Fungal Diversity 64:305-315.

Soil Survey Staff. 1995. Order 1 soil survey of the Luquillo long-term ecological research grid, Puerto Rico. USDA, Natural Resources Conservation Service, Lincoln, Nebraska, USA.

Swenson, N. G., et al. 2012. Temporal turnover in the composition of tropical tree communities: functional determinism and phylogenetic stochasticity. Ecology 93:490-499.

Tchabi, A., D. Coyne, F. Hountondji, L. Lawouin, A. Wiemken, and F. Oehl. 2008. Arbuscular mycorrhizal fungal communities in sub-Saharan savannas of Benin, West Africa, as affected by agricultural land use intensity and ecological zone. Mycorrhiza 18:181-195.

Tedersoo, L., M. Bahram, S. Polme, and E. Al. 2014. Global diversity and geography of soil fungi. Science 346: 1052-1053.

Thompson, J., et al. 2002. Land use history, environment, and tree composition in a tropical forest. Ecological Applications 12:1344-1363.

Toju, H., et al. 2013. How are plant and fungal communities linked to each other in belowground ecosystems? A massively parallel pyrosequencing analysis of the association specificity of root-associated fungi and their host plants. Ecology and Evolution 3:3112-3124.

Urbanová, M., J. Šnajdr, and P. Baldrian. 2015. Composition of fungal and bacterial communities in forest litter and soil is largely determined by dominant trees. Soil Biology and Biochemistry 84:53-64.

Uriarte, M., C. Canham, J. Thompson, J. K. Zimmerman, and N. Brokaw. 2005. Seedling recruitment in a hurricanedriven tropical forest: light limitation, density-dependence and the spatial distribution of parent trees. Journal of Ecology 93:291-304.

Uriarte, M., B. L. Turner, J. Thompson, and J. K. Zimmerman. 2015. Linking spatial patterns of leaf litterfall and soil nutrients in a tropical forest: a neighborhood approach. Ecological Applications 25:2022-2034.

Vályi, K., M. C. Rillig, and S. Hempel. 2015. Land-use intensity and host plant identity interactively shape communities of arbuscular mycorrhizal fungi in roots of grassland plants. New Phytologist 205:1577-1586.

Van der Gast, C. J., P. Gosling, B. Tiwari, and G. D. Bending. 2011. Spatial scaling of arbuscular mycorrhizal fungal diversity is affected by farming practice. Environmental Microbiology 13:241-249.

Vasileiadis, S., E. Puglisi, M. Arena, F. Cappa, J. A. van Veen, P. S. Cocconcelli, and M. Trevisan. 2013. Soil microbial diversity patterns of a lowland spring environment. FEMS Microbiology Ecology 86:172-184.

Vellend, M., et al. 2007. Homogenization of forest plant communities and weakening of species? Environment relationships via agricultural land use Journal of Ecology 95:565-573.

Verbruggen, E., M. G. A. Van Der Heijden, J. T. Weedon, G. A. Kowalchuk, and W. F. M. Rö-Ling. 2012. Community assembly, species richness and nestedness of arbuscular mycorrhizal fungi in agricultural soils. Molecular Ecology 21:2341-2353

Violi, H. A., et al. 2008. Disturbance changes arbuscular mycorrhizal fungal phenology and soil glomalin concentrations but not fungal spore composition in montane 
rainforests in Veracruz and Chiapas, Mexico. Forest Ecology and Management 254:276-290.

Wagg, C., C. Barendregt, J. Jansa, and M. G. A. van der Heijden. 2015. Complementarity in both plant and mycorrhizal fungal communities are not necessarily increased by diversity in the other. Journal of Ecology 103:1233-1244.

Waldrop, M. P., D. R. Zak, C. B. Blackwood, C. D. Curtis, and D. Tilman. 2006. Resource availability controls fungal diversity across a plant diversity gradient. Ecology Letters 9:1127-1135.

Walsh, R. P. D. 1996. The tropical rainforest: an ecological study. Cambridge University Press, Cambridge, UK.

Wardle, D. A., R. D. Bardgett, J. N. Klironomos, and H. Seta. 2011. Ecological linkages between aboveground and belowground biota. Science 304:1629-1633.
Waring, B. G., R. Adams, S. Branco, and J. S. Powers. 2016. Scale-dependent variation in nitrogen cycling and soil fungal communities along gradients of forest composition and age in regenerating tropical dry forests. New Phytologist 209:845-854.

Whittaker, R. H. 1960. Vegetation of the Siskiyou Mountains, Oregon and California. Ecological Monographs 30:279-338.

Zheng, C., B. Ji, J. Zhang, F. Zhang, and J. D. Bever. 2015. Shading decreases plant carbon preferential allocation towards the most beneficial mycorrhizal mutualist. New Phytologist 205:361-368.

Zink, T. A., and M. F. Allen. 1998. The effects of organic amendments on the restoration of a disturbed coastal sage scrub habitat. Restoration Ecology 6:52-58.

\section{SUPPORTING INFORMATION}

Additional supporting information may be found in the online version of this article at http://onlinelibrary.wiley.com/ doi/10.1890/15-1397.1/suppinfo 